\title{
Monitoring Age-Related Susceptibility of Young Mice To Oral Salmonella enterica Serovar Typhimurium Infection Using an In Vivo Murine Model
}

\author{
STACY M. BURNS-GUYDISH, ISOKEN N. OLOMU, HUI ZHAO, RONALD J. WONG, \\ DAVID K. STEVENSON, AND CHRISTOPHER H. CONTAG \\ Division of Neonatal and Developmental Medicine [S.M.B., H.Z., R.J.W., D.K.S., C.H.C.], Department of \\ Pediatrics, Stanford University School of Medicine, Stanford, California 94305; and Department of \\ Pediatrics [I.N.O.], Michigan State University, East Lansing, Michigan 48824
}

\begin{abstract}
ABST
Neonates and young children are acutely susceptible to infec-
tions by gastrointestinal bacterial pathogens, such as Salmonella
enterica serovar Typhimurium ( $S$. typhimurium). To reveal age-
related differences in susceptibility to this pathogen, we used in
vivo bioluminescence imaging (BLI) to monitor the progression
of infection in neonatal (1-wk-old), suckling (2-wk-old), juvenile
(4-wk-old), and adult (6-wk-old) BALB/c mice. Mice were
orally infected with various doses of a bioluminescent-labeled
wild-type or mutant $S$. typhimurium strain, and progression of
infection was monitored by BLI for 2 wks. We found that
neonatal and suckling mice were more susceptible to the wild-
type strain at inoculum sizes 4 and 2 log 10 's lower for neonatal
and suckling mice, respectively, than those for adult mice. At the
lower inocula, newborn mice showed disseminated systemic
infection as indicated by the pattern of photon emission assessed
by BLI, whereas no bioluminescent signals were detectable in
\end{abstract}
\section{ABSTRACT}

adult mice. In addition, an $\operatorname{org}^{-}$mutant strain of $S$. typhimurium with reduced virulence in adult mice produced systemic infection in newborn, suckling, and juvenile mice. Furthermore, as low as $3 \log _{10}$ CFU could be detected by BLI in tissue. The present study demonstrates that susceptibility to $S$. typhimurium infection decreases with age. Also, we established that BLI can be used to monitor the progression of infection in mice. Thus, this model of age-related susceptibility to $S$. typhimurium using BLI can be used to advance our understanding of the mechanisms involved in newborn susceptibility to infection. (Pediatr Res 58: 153-158, 2005)
BLI, bioluminescence imaging
Abbreviations
CFU, colony-forming units
LB, Luria broth

Newborn and young children are acutely susceptible to infections by gastrointestinal microbes, such as Salmonella spp. The course of these infections in adults is usually selflimiting, but in neonates, it may progress to disseminated systemic disease $(1,2)$. Moreover, infected newborns and infants are at high risk for complications such as severe sepsis, meningitis, and intracranial sequelae (1,3-5). Gram-negative enteric bacilli are one of the leading causes of neonatal sepsis in both developing and developed countries $(3,6)$, where the mortality rate of infants as a result of neonatal sepsis ranges from 15 to $50 \%$ (3).

Received August 19, 2004; accepted October 13, 2004.

Correspondence: Stacy M. Burns-Guydish, Ph.D., Department of Pediatrics, Division of Neonatal and Developmental Medicine, Stanford University School of Medicine, 300 Pasteur Drive, S-230 Grant Bldg., Stanford, CA 94305-5208; e-mail: smburns@stanford.edu.

This work was supported by the National Institutes of Health Grant HD37543 and unrestricted funds from the Hess Research Fund and the Mary L. Johnson Research Fund.

DOI: 10.1203/01.PDR.0000157725.44213.C4
The exact mechanisms of increased neonatal susceptibility and the progression to serious life-threatening diseases remain essentially unknown. We hypothesized that key protective mediators that are present in adults may be absent in neonates as a result of immaturity of their neonatal host immune system. However, other factors, such as differences in resident gastrointestinal flora (7), gastric $\mathrm{pH}(8)$, gastric emptying rates, and the intestinal barrier, may also play a role in susceptibility $(7,9,10)$. Because age-related susceptibility is not well understood, a well-defined neonatal animal model of bacterial infection would advance our understanding of the mechanisms involved in this process.

Infection of mice with Salmonella enterica serovar Typhimurium (S. typhimurium), which causes a human typhoid-like disease in BALB/c mice, is an ideal model system. Both host response and pathogen genetics have been well studied, resulting in a well-defined system that is easily adapted to evaluate the maturation steps in the development of effective host defenses.

Traditional susceptibility studies use as the end point the measurement of the dose at which $50 \%$ of animals die $\left(\mathrm{LD}_{50}\right)$. 
This model, however, does not afford the ability to monitor infection and spread to distant organs. To establish an in vivo neonatal model of infection, we used a noninvasive imaging technology to monitor $S$. typhimurium infection in BALB/c mice of various ages. The use of in vivo bioluminescence imaging (BLI) was first demonstrated using three strains of bioluminescent $S$. typhimurium, which were shown to elicit distinct patterns of infection in adult mice (11). The advantage of BLI is that the technology can not only reveal spatiotemporal patterns of infection but also guide the timing of ex vivo assays and the selection of tissues for labor-intensive and time-consuming assays. Because study groups survive noninvasive assays, this approach also offers the opportunity to study the same group of animals over the entire disease course (12-14).

\section{METHODS}

Bacterial strains. Three strains of S. typhimurium strain were selected on the basis of known and predicted virulence properties previously characterized in adult BALB/c mice $(15,16)$. The wild-type virulent strain SL1344 has been shown to cause systemic disease after oral inoculation of adult BALB/c mice (17). BJ66, an $\operatorname{org} A^{-}$mutant of SL1344, is $>60$-fold reduced in virulence compared with SL1344 after oral infection (18). LB5000, a LT2 laboratory strain of S. typhimurium that has multiple auxotrophic mutations and does not result in systemic infection of adult mice, was used as a control $(15,19)$. SL1344, BJ66, and LB5000 were obtained from Dr. B.A.D. Stocker (Stanford University, Stanford, CA).

Labeling of S. typhimurium strains. Two S. typhimurium strains were labeled via chromosomal integration of a Tn5 transposon (Table 1). The suicide vector pUT-Tn5-luxCDABE-Km $(20,21)$ was engineered to constitutively express the luxCDABE genes required for the production of bioluminescent light (22) by 5 ' insertion of the EM7 promoter (Invitrogen, Carlsbad, CA), a synthetic promoter developed for constitutive gene expression. SL1344 and BJ66 were labeled following the method described previously (23). The gene of chromosomal integration of the transposon for SL1344-Tn5lux was

Table 1. Age-related susceptibility of BALB/c mice to $\mathrm{S}$. typhimurium strains

\begin{tabular}{|c|c|c|c|c|c|}
\hline & \multirow[b]{2}{*}{$\log _{10} \mathrm{CFU}$} & \multicolumn{4}{|c|}{ Age } \\
\hline & & $1 \mathrm{wk}$ & $2 \mathrm{wk}$ & $4 \mathrm{wk}$ & $6 \mathrm{wk}$ \\
\hline \multirow[t]{3}{*}{ SL1344 } & 4.6 & & & & $3 / 5$ \\
\hline & 5.6 & & & & $4 / 5$ \\
\hline & 6.6 & & & & $5 / 5$ \\
\hline \multirow[t]{6}{*}{ SL1344-Tn5lux } & $1.6-1.9$ & $4 / 5^{*}$ & $0 / 5$ & $0 / 5$ & \\
\hline & 2.5 & $5 / 5$ & & & \\
\hline & 3.6 & $5 / 5$ & $5 / 5 \ddagger$ & & \\
\hline & 4.6 & & & & $1 / 5$ \\
\hline & 5.6 & & $5 / 5$ & & $4 / 5 \ddagger$ \\
\hline & 6.1 & & $5 / 5$ & $5 / 5$ & \\
\hline \multirow[t]{3}{*}{ BJ66 } & 6.2 & & & & $1 / 5$ \\
\hline & $7.2-7.4$ & & $5 / 5$ & $3 / 5$ & $2 / 5$ \\
\hline & 8.2 & & & & $3 / 5$ \\
\hline \multirow[t]{6}{*}{ BJ66-Tn5lux } & 2.3 & & $4 / 5$ & & \\
\hline & $3.3-3.6$ & & $4 / 5$ & & \\
\hline & 4.3 & & $4 / 5$ & & \\
\hline & $5.3-5.6$ & $5 / 5 \dagger$ & $5 / 5 \dagger$ & $0 / 5$ & $0 / 5$ \\
\hline & $6.1-7.4$ & $5 / 5$ & $5 / 5$ & $5 / 5 \ddagger$ & $1 / 4$ \\
\hline & 8.9 & & & & $2 / 5$ \\
\hline LB5000 & 7.5 & $0 / 5$ & $0 / 5$ & & $0 / 5$ \\
\hline
\end{tabular}

$* p \leq 0.05$ vs $2-, 4$, and 6-wk-old mice.

$\dagger p \leq 0.05$ vs 4- and 6-wk-old mice.

$\ddagger p \leq 0.05$ vs lower dose. identified as the hha gene. After completion of a majority of our experiments, Hha was subsequently identified by Fahlen $e t$ al. (24) to be a negative regulator of invasion gene expression, and an hha mutant was more invasive in vitro than wild-type $S$. typhimurium. In addition, we found no significant differences in infection between labeled strains and their parent strain (Table 1).

Oral infection. BALB/c mice were obtained from the breeding colony of the Department of Comparative Medicine (Stanford, CA). All mice were maintained under strict adherence to IACUC guidelines. Labeled S. typhimurium strains were grown in static conditions in Luria broth (LB) medium (GIBCO BRL, Rockville, MD) to induce invasiveness (25) at $37^{\circ} \mathrm{C}$ for $2-3 \mathrm{~h}$ to an OD of $0.2-0.3\left(\mathrm{OD}_{600}\right)$. Mice were infected orally by feeding an inoculum at doses ranging from $1-3 \times 10^{2}$ to $10^{9}$ colony forming units (CFU) in $10 \mu \mathrm{L}$ of LB (dose confirmed by plating aliquots of inocula) using a pipette tip placed in the mouth of animals. A volume of $10 \mu \mathrm{L}$ can be delivered reliably to 1- and 2-wk-old mice. This inoculation method was chosen over oral gavage because of the difficulty and potential complications associated with gavage feeding young, preweaning mice, such as esophageal perforation and/or aspiration pneumonitis. After inoculation of mice $(n=4-5$ for each dose), infection progression was monitored daily by BLI (as described below) for $8 \mathrm{~d}$ and/or up to $14 \mathrm{~d}$ for infections that did not result in overt disease. Mice were killed when systemic dissemination of infection was apparent, as revealed by BLI, and/or when mice displayed overt signs of systemic disease, such as ruffled fur, lethargy, hunched posture, ataxia, tremor, and eye discharge, for up to $30 \mathrm{~d}$ after inoculation (26).

CFU determinations. Time points and tissues were selected for determinations of $\mathrm{CFU}$ as guided by the spatiotemporal patterns revealed by BLI. After mice were killed and tissues were removed, intestinal tissues were flushed with PBS. Tissues were weighed and then homogenized in sterile stomacher bags (Fischer Scientific, Santa Clara, CA) that contained PBS. Dilutions were performed, and samples were plated on LB agar plates. Plates were incubated overnight at $37^{\circ} \mathrm{C}$, luminescent colonies were counted, and CFU were determined.

In vivo BLI. In vivo BLI was performed using an In Vivo Imaging System (IVIS100) equipped with a cooled CCD camera and a Navitar f0.9 lens (Xenogen Corp., Alameda, CA) as previously described (11). Mice were anesthetized with pentobarbital at the following doses: $18-35,25-40$, and $50-70 \mathrm{mg} / \mathrm{kg}$ for 1-, 2-, 4-, and 6-wk-old mice, respectively, and then placed in the In Vivo Imaging System. A grayscale reference image was first taken under weak illumination, followed by a 5-min image of light (emitted photons) transmitted through the animal's tissues taken in the dark. After photon collection, a pseudocolor representation of light intensity (red, most intense; blue, least intense) was superimposed over the grayscale body surface reference image. Data acquisition and analyses were performed using the LivingImage (Xenogen Corp.) software that runs as an overlay on the IgorPro analysis package (Wavemetrics, Seattle, WA).

Statistical analyses. For susceptibility studies, $\chi^{2}$ analyses were performed comparing each inoculum dose and rate of infectivity for each age and between all ages of mice. Fisher's exact $t$ test then was used to determine the level of significance $(p \leq 0.05)$. Linear regression analysis was performed to determine the correlation between tissue luminescence and recoverable CFU. Significant differences in CFU between tissues of infected mice were determined by unpaired $t$ test $(p \leq 0.05)$. All computations were performed using StatView v. 5.0 (SAS Institute Inc., Cary, NC).

\section{RESULTS}

Bioluminescent labeling of S. typhimurium strains. Three strains of S. typhimurium - SL1344, an isogenic orgA- mutant strain, BJ66, and a nonvirulent strain, LB5000 - representing a broad range of virulence to $\mathrm{BALB} / \mathrm{c}$ mice, were selected to reveal age-related differences in susceptibility and to further test susceptibility of young mice to mutant strains. SL1344 and BJ66 were labeled as described in "Methods." Because no significant differences in infection were observed between the labeled and parent strains, we concluded that the labeled strains maintained the virulence properties of the parent strain ("Methods" and Table 1).

Monitoring S. typhimurium infection using BLI. For demonstrating the ability to monitor infection by BLI, adult $\mathrm{BALB} / \mathrm{c}$ mice were orally inoculated with a lethal dose of SL1344-Tn5lux of $5.6 \log _{10}$ CFU (Fig. 1A). BLI revealed the 
A.

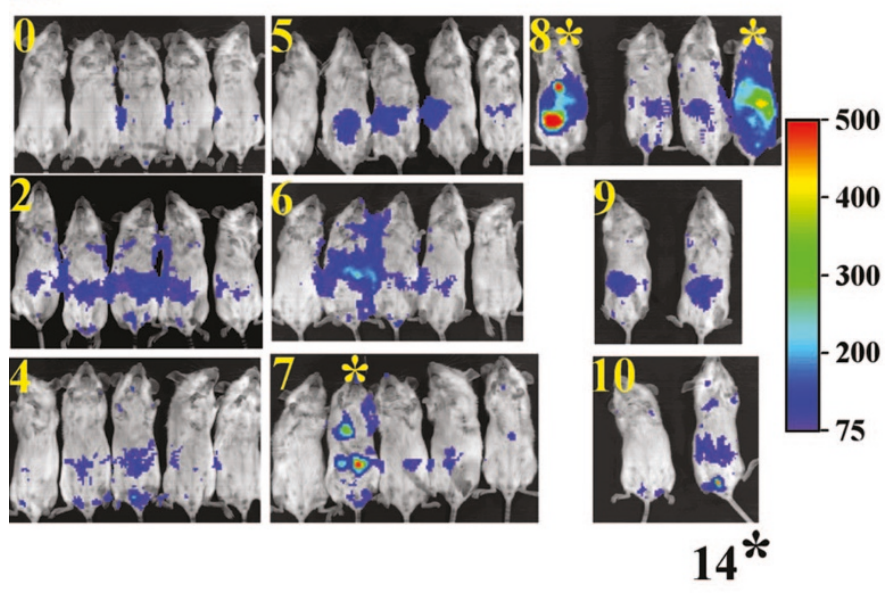

B.

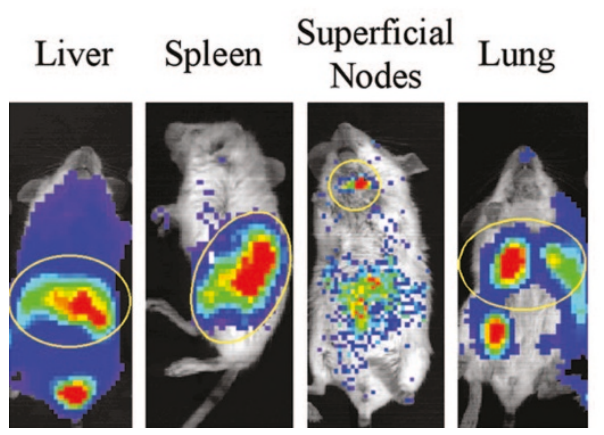

Figure 1. Monitoring oral S. typhimurium disease progression. Six-week-old $\mathrm{BALB} / \mathrm{c}$ mice were inoculated by oral administration of $10^{5} \mathrm{CFU}$ of the bioluminescent-labeled wild-type S. typhimurium strain SL1344-Tn5lux and monitored by BLI $1 \mathrm{~h}$ after inoculation (day 0 ) and daily over a 14-d time course $(A)$. Days after inoculation are indicated in the top left corner of each image. Light intensity is represented by a color scale in counts. *Day of killing or death. Patterns of light emission indicate the progression of infection from the abdominal region (initial site) to secondary tissue sites, which is indicative of systemic infection. Examples of secondary sites of infection (liver, spleen, superficial cervical lymph nodes, and lung) are shown by the yellow circles in $B$ from 2-wk-old (suckling) mice that were infected with SL1344-Tn5lux. (Note: mice were inoculated at various doses, and images were taken at different time points after inoculation.)

spatial and temporal progression of infection as shown by luminescent signals detected in the abdominal region early in the disease course (day 2) and then at secondary sites late in the disease course-indicative of systemic spread to distant tissues, such as the liver, spleen, superficial cervical lymph nodes, and lung (Fig. 1B).

Sensitivity of detection by BLI. The numbers of labeled $S$. typhimurium detectable by BLI were determined for the spleen (large, dark tissue) and the superficial cervical lymph node (small, translucent tissue). Tissues from mice with and without detectable bioluminescent signals were selected for subsequent $\mathrm{CFU}$ determinations to determine the minimal detectable level of CFU by BLI. Bioluminescent signals were quantified over the region of the spleen for 2-wk-old mice $(n=10)$ with a luminescent signal over background, and the spleen was removed for CFU determination. Signal intensity was plotted relative to $\mathrm{CFU}$ (Fig. 2A). Images of two representative mice

\section{A. Spleen CFU versus Luminescent Counts}

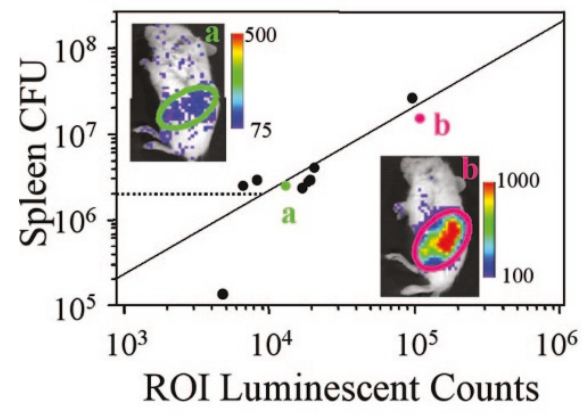

\section{B. Detectable CFU in Lymph Nodes}

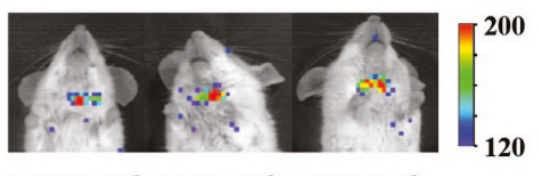

CFU: $8.8 \times 10^{2}<1.0 \times 10^{3} \quad 3.5 \times 10^{3}$

Figure 2. Detectable CFU in the spleen of 2-wk-old (suckling) BALB/c mice. (A) Two-week-old (suckling) mice $(n=10)$ were infected with SL1344Tn5lux (lethal dose ranging from $10^{4}$ to $10^{5} \mathrm{CFU}$ ) and luminescent signals (over background) emitting from the anatomic region of the spleen (colored ovals) were quantified as total counts, then compared with CFU determined from the harvested spleens, and are shown in the scatter plot. Regression analysis showed a strong correlation between total counts and CFU $(r=0.914$, $p=0.0002$ ). The dotted line shows that the minimal detectable CFU by BLI is $1 \times 10^{6}$. Two representative images ( $\mathrm{a}$ and $\mathrm{b}$ ) are shown with their luminescent signals plotted in green and red, respectively. $(B)$ Representative images of mice with luminescent signals emanating from the superficial cervical lymph nodes. Total counts and the CFU isolated from the lymph nodes are shown below the images. Light intensity is represented by a color scale in counts.

are shown in Fig. $2 A$ with corresponding $\mathrm{CFU}$ data. From regression analysis, the minimum detectable number of $\mathrm{CFU}$ from the spleens of 2-wk-old mice by BLI was $6.3 \log _{10} \mathrm{CFU}$ for SL1344-Tn5lux $(r=0.914, p=0.0002)$. A similar analysis of adult mice $(n=27)$ that were infected with the same labeled strain confirmed that the minimum detectable CFU from the spleens was also $\sim 6.3 \log _{10}$ CFU (data not shown). Minimal detectable CFU in the superficial cervical lymph nodes of 2-wk-old mice $(n=3)$ was $<3 \log _{10}$ CFU (Fig. $\left.2 B\right)$.

Age-related susceptibility of BALB/c Mice to S. typhimurium. For assessing the susceptibility of young mice to $S$. typhimurium, BALB/c mice at four different ages, representing neonatal (1-wk-old), suckling (2-wk-old), juvenile (4-wk-old), and adult mice (6-wk-old), were orally inoculated with various doses of the labeled wild-type strain SL1344-Tn5lux and imaged daily. Susceptibility was defined as when $80 \%$ of mice displayed signs and symptoms of overt disease and/or spread of infection as monitored by BLI. Neonatal and suckling mice succumbed to inoculum sizes of 1.6 and $3.6 \log _{10} \mathrm{CFU}$, respectively, compared with adults that are susceptible to 5.6 $\log _{10}$ CFU ( $p \leq 0.05$; Table 1). Thus, 1 - and 2-wk-old mice are susceptible to 4 and $2 \log _{10}$ 's less CFU than are adult mice, respectively.

Age-related susceptibility of BALB/c mice to a reduced virulent strain of S. typhimurium. BLI of mice that were 
infected with $5.4 \log _{10}$ CFU of the labeled mutant strain BJ66-Tn5lux showed that 1- and 2-wk-old mice had high signal intensities in the abdominal region and distant sites indicative of systemic infection. In contrast, 4- and 6-wk-old mice had no detectable luminescent signals and, therefore, no sign of infection or systemic spread (Fig. 3A). When inoculated with $7.4 \log _{10}$ CFU, 1-, 2-, and 4-wk-old mice had luminescent signals indicative of systemic infection, whereas 6-wk-old mice show no signals and no signs of infection (Fig. $3 B$ ). In addition, temporal analysis documented in Fig. $3 B$ revealed that younger mice succumbed to infection at earlier time points compared with juvenile mice (an average of $5.7 \mathrm{~d}$ for 1- and 2 -wk-old mice versus $8.0 \mathrm{~d}$ for 4-wk-old mice; $p \leq 0.05$ ).

Further analysis of systemic infection in 2-wk-old mice that were infected with reduced inoculum sizes of BJ66-Tn5lux revealed that they were susceptible to as few as $2.3 \log _{10} \mathrm{CFU}$ (Table 1). Because 6-wk-old mice were not susceptible to an inoculum size of $8.9 \log _{10} \mathrm{CFU}$, there is a $>6 \log _{10}$ difference in susceptibility between 2- and 6-wk-old mice to the mutant labeled strain BJ66-Tn5lux. It is interesting that 2-wk-old mice were as susceptible to the $\operatorname{org} A^{-}$mutant as they were to the wild-type strain.

Because younger mice showed an increased susceptibility to the wild-type and mutant strain of $S$. typhimurium, we tested susceptibility to the nonlabeled $\operatorname{org} A^{-}$mutant strain and to a nonvirulent common lab strain, LB5000. Two-week-old mice were as susceptible to $7.4 \log _{10} \mathrm{CFU}$ of BJ66 compared with
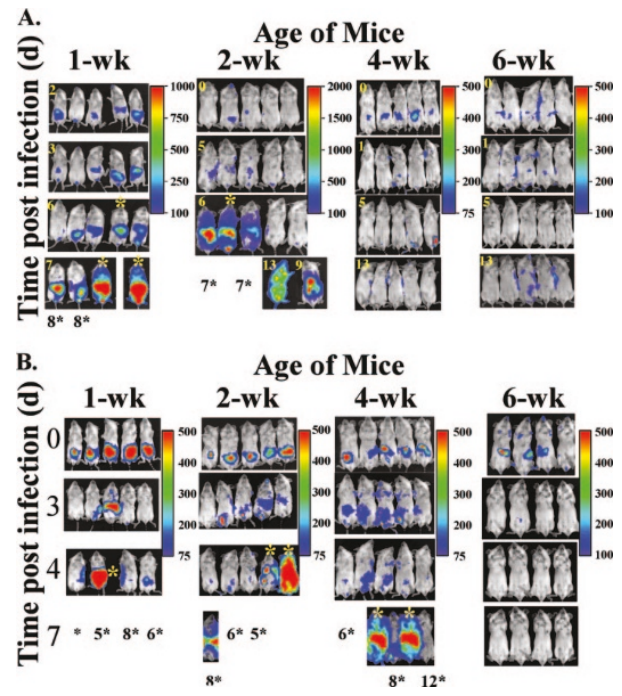

Figure 3. (A) Oral Inoculation with $10^{5}$ BJ66Tn5lux. (B) Oral Inoculation with $10^{7}$ BJ66Tn5lux. Age-related susceptibility of BALB/c mice to oral inoculation with BJ66Tn5lux. Labeled BJ66-Tn5lux was orally inoculated into 1- (neonatal), 2- (suckling), 4- (juvenile), and 6-wk-old (adult) mice ( $n=4-5$ per group) at a dose of $10^{5}(A)$ or $10^{7}(B)$. Mice were imaged $1 \mathrm{~h}$ after inoculation (day 0 ) and daily over a 14-d time course. Days after inoculation are indicated in the top left corner of each image $(A)$ or in the left column $(B)$. A dose of $10^{5}$ BJ66 did not cause systemic disease in 4- and 6-wk-old mice as indicated by no or low signals throughout the study period. In contrast, signals were strong and persistent in 1- and 2-wk-old mice throughout the study period. At a dose of $10^{7}, 1-, 2-$, and 4-wk-old mice were susceptible as shown by the intense and persistent luminescence in the abdominal region throughout the study period. In contrast, weak signals were observed only $1 \mathrm{~h}$ after inoculation in 6-wk-old mice and therefore were not susceptible. Light intensity is represented by a color scale in total counts. *Day of killing or death. the labeled strain, BJ66-Tn5lux (Table 1). In addition, mice were not susceptible to an inoculum size of $7 \log _{10} \mathrm{CFU}$ of LB5000 at all ages.

Assessing infection of 2- and 6-wk-old mice by tissue CFU determination. BLI of infected 2- and 6-wk-old mice revealed low bioluminescent signals from the abdominal region during the first $4 \mathrm{~d}$ of infection. Therefore, we determined CFU from selected tissues on days 1 and 4 after infection. To assess disease burden in suckling versus adult mice, we chose an inoculum size of $10^{4} \mathrm{CFU}$ of SL1344-Tn5lux, a dose above the $\mathrm{LD}_{50}$ of suckling mice and below for adult mice (Table 1). Intestinal tissues (small intestine, cecum, colon), spleen, and liver were removed from orally infected 2- and 6-wk-old mice ( $n=5$ per age group). At day 1 after infection, intestinal tissues from 2-wk-old mice had $>5 \log _{10} \mathrm{CFU} / \mathrm{g}$ tissue compared with no detectable CFU $(p<0.0001)$ in 6-wk-old mice (Table 2). Spleen and liver of both 2- and 6-wk-old mice had no detectable CFU. By day 4 after infection, bioluminescent bacteria were present in the intestinal tissues, spleen, and liver in 2-wk-old mice but not in 6-wk-old mice (Table 2). All CFU comparisons of 2- and 6-wk-old mice at day 4 after inoculation had $p$ values that were significant except for the cecum $(p=$ 0.056).

\section{DISCUSSION}

BLI is a noninvasive and versatile in vivo imaging modality. Light transmission through tissues depends on the wavelength of luciferase emission and depth of tissue. Thus, photons that emit from superficial and translucent tissues, such as lymph nodes, bones, or skin, will transmit with less scattering and absorption than from opaque organs such as liver and spleen (27-30). Here, we used BLI to reveal the tempo of disease progression and location of sites of infection as well as to guide the timing and selection of tissues for ex vivo assays. We found that BLI is a useful tool to understand age-related differences in susceptibility to infection without the need to use death as an end point, thus reducing the suffering and number of animals used compared with conventional blind $\mathrm{LD}_{50}$ studies.

In addition, by using BLI, we were able predict the number of bacteria (CFU) in murine tissues and confirm these predictions by traditional CFU determination. In superficial cervical lymph nodes, we detected as few as $10^{3} \mathrm{CFU}$. Using the entire organ for CFU measurements, we were able to detect a minimum of $10^{6} \mathrm{CFU}$ in the spleens in both 2-wk-old and adult mice. However, for intestinal tissues, the correlation between CFU and signal intensity was poor and likely due to variable positioning of the intestine within the abdomen, resulting in inconsistent signal intensities, or to the presence of bacteria in an anaerobic compartment, where the organisms express the reporter gene but do not produce light as a result of oxygen limitation (11). Nonetheless, luminescent signals can be detected over the abdominal region of 4- and 6-wk-old mice within hours after inoculation with $10^{5} \mathrm{CFU}$ of BJ66-Tn5lux (Fig. 2A). Detectable numbers of luminescent bacteria in in vivo models have the potential to improve. For example, in BLI models of cancer, as low as a few hundred luminescent cancer cells can be detected in vivo (31). 
Table 2. CFU/g of tissue from 2- and 6-wk-old BALB/c mice at days 1 and 4 after oral inoculation with 104 SL1344-Tn5lux

\begin{tabular}{|c|c|c|c|c|c|c|}
\hline \multirow[b]{2}{*}{ Tissue } & \multicolumn{6}{|c|}{$\log _{10} \mathrm{CFU} / \mathrm{g}^{*}$} \\
\hline & 2-wk-old & 6-wk-old & $p$ value & 2-wk-old & 6-wk-old & $p$ value \\
\hline Spleen & ND & ND & - & $4.9 \pm 0.9$ & ND & 0.0081 \\
\hline Small intestine & $5.0 \pm 0.6$ & ND & $<0.0001$ & $4.6 \pm 1.6$ & ND & 0.0046 \\
\hline Cecum & $5.4 \pm 0.7$ & ND & $<0.0001$ & $3.4 \pm 1.7 \dagger$ & ND & 0.0560 \\
\hline
\end{tabular}

* Values are mean \pm SD of $\log _{10} \mathrm{CFU}(n=5$ per group) except $\dagger(n=3$ per group) and $\ddagger(n=4$ per group) for tissues of 2 - (suckling) and 6 -wk-old (adult) BALB/c mice at days 1 and 4 after oral inoculation with $10^{4}$ SL1344-Tn5lux (a dose below and above the LD $_{50}$ for adult and suckling mice, respectively). ND, not detected with a detectable limit of $50 \mathrm{CFU}$. p values were determined for comparisons of CFU from 2- and 6-wk-old mouse tissue (using $50 \mathrm{CFU}$ for the undetected samples) by an unpaired $t$ test.

In this study, we applied BLI with an infection technique and developed a neonatal model of bacterial infection. Using two strains of bioluminescent-labeled S. typhimurium with differing abilities to cause disease in adult mice, we found that 1- and 2-wk-old BALB/c mice are more susceptible to inocula orders of magnitude smaller than those for adult mice. Twoweek-old mice at days 1 and 4 after infection also had significantly greater CFU compared with adult mice from intestinal tissue (days 1 and 4), liver (day 4), and spleen (day 4).

In addition, BLI revealed that the tempo of progression and dissemination of infection in young mice was earlier and greater compared with that of adult mice. We observed that susceptibility to infection decreased with age, as 1-wk-old mice are more susceptible to doses orders of magnitude lower than 4-wk-old mice. Garland et al. (32) also found that rats that were 2 to 12 wks of age and inoculated with $10^{9} \mathrm{~S}$. enteriditis by the orogastric route had a mortality rate dependent on age. The age at weaning ( $3 \mathrm{wks})$ has been thought to be an important time of neonatal development and acquisition of resistance to infection. This seems to hold true in our model as well. In addition, 4-wk-old mice were more susceptible than 6-wk-old mice to BJ66, a mutant strain of SL1344 that was selected for its inability to invade mammalian cells $(18,33)$. This suggests that steps in the maturation process and factors that are necessary to limit the course of infection are not fully developed until $6 \mathrm{wk}$ of age.

Young mice were more susceptible not only to the wild-type strain SL1344 but also to a mutant strain, BJ66. In fact, the difference in susceptibility between 2- and 6-wk-old mice was even greater for infection with BJ66-Tn5lux than the wild-type strain. Two-week-old mice were $2 \log _{10}$ 's more susceptible to SL1344-Tn5lux versus $6 \log _{10}$ 's more susceptible to BJ66Tn5lux than 6-wk-old mice. Susceptibility was not due to the presence of the lux genes or chromosomal insertion site because 2- and 4-wk-old mice were also susceptible to the unlabeled BJ66 strain. That neonatal mice are more susceptible to reduced numbers of a mutant $S$. typhimurium raises concerns regarding the potential use of a Salmonella-based vaccine in vulnerable age groups. These results suggest that potential vaccine strains may pose a threat to young children and neonates. However, studies with labeled strains, SL7207, a $p h o P$ mutant, and a $t p p R$ mutant strain, at inoculum sizes up to $10^{9}$ do not seem to harm young mice (Burns et al., submitted).
The $\operatorname{org} A$ mutation of BJ66 causes a defect in its ability to invade the $\mathrm{M}$ cells of Peyer's patches. Intraperitoneal inoculation of this mutant does not affect its virulence (18). Our data suggest that the invasive phenotype of SL1344 and BJ66 in young mice is similar and that the bacteria may be gaining systemic access by either breaching the intestinal barrier as a result of physiologic differences between the neonatal and adult gut or of lack of immune response to the pathogen. Physiology of the immature gut, such as its neutral $\mathrm{pH}$ environment in neonates (8), may account for their increased susceptibility to small inocula, yet the increased susceptibility of 4- compared with 6-wk-old mice to the mutant strain is more likely due to differences in the maturity of host defenses $(10,34)$ or in cell populations in the neonatal gut versus that of the adult (35) because physiologic differences between the juvenile and the adult gut are less distinct.

The establishment of the resident gut microflora may also contribute to an enhanced resistance to bacterial infection in the adult (32). Although this resistance may be due to a protective role of resident microflora by inhibition of colonization $(32,36)$, recent evidence implicates that indigenous microbes may also modulate the expression of host genes from intestinal cells such as Paneth cells (37-39), which are an important component of gut innate immunity. In addition, intestinal $\mathrm{T}$ cell colonization, although not well understood, seems to be dependent on the presence of normal microbial flora $(40,41)$. Thus, the colonization of microflora may serve to develop and prepare the immature neonatal immune system for response to infection.

\section{CONCLUSION}

In summary, we have established and characterized a novel neonatal model for studying age-related susceptibility using noninvasive BLI. We have shown that neonatal and suckling mice are acutely susceptible to both a wild-type and a mutant strain of S. typhimurium. A model of age-related susceptibility to infection, whereby we can not only monitor the progression and spread of infection in vivo but also guide the specific targeting of time points and tissues for ex vivo analyses, will allow us to identify the key protective factors that are lacking in the neonate. 
Acknowledgments. We thank the late Bruce A.D. Stocker for the Salmonella strains.

\section{REFERENCES}

1. Blaser MJ, Feldman RA 1981 From the centers for disease control. Salmonella bacteremia: reports to the Centers for Disease Control, 1968-1979. J Infect Dis 143:743-746

2. Hargrett-Bean NT, Pavia AT, Tauxe RV 1988 Salmonella isolates from humans in the United States, 1984-1986. MMWR CDC Surveill Summ 37:25-31

3. Klein JO 1990 Current antibacterial therapy for neonatal sepsis and meningitis. Pediatr Infect Dis J 9:783-784

4. Wessalowski R, Thomas L, Kivit J, Voit T 1993 Multiple brain abscesses caused by Salmonella enteritidis in a neonate: successful treatment with ciprofloxacin. Pediat Infect Dis J 12:683-688

5. West SE, Goodkin R, Kaplan AM 1977 Neonatal Salmonella meningitis complicated by cerebral abscesses. West J Med 127:142-145

6. Moreno MT, Vargas S, Poveda R, Saez-Llorens X 1994 Neonatal sepsis and meningitis in a developing Latin American country. Pediatr Infect Dis J 13:516-520

7. Cebra JJ 1999 Influences of microbiota on intestinal immune system development. Am J Clin Nutr 69:1046S-1051S

8. Kelly EJ, Newell SJ, Brownlee KG, Primrose JN, Dear PR 1993 Gastric acid secretion in preterm infants. Early Hum Dev 35:215-220

9. Berseth CL 1996 Gastrointestinal motility in the neonate. Clin Perinatol 23:179-190

10. Wilson CB, Westall J, Johnston L, Lewis DB, Dower SK, Alpert AR 1986 Decreased production of interferon-gamma by human neonatal cells. Intrinsic and regulatory deficiencies. J Clin Invest 77:860-867

11. Contag CH, Contag PR, Mullins JI, Spilman SD, Stevenson DK, Benaron DA 1995 Photonic detection of bacterial pathogens in living hosts. Mol Microbiol 18:593-603

12. Contag CH, Spilman SD, Contag PR, Oshiro M, Eames B, Dennery P, Stevenson DK, Benaron DA 1997 Visualizing gene expression in living mammals using a bioluminescent reporter. Photochem Photobiol 66:523-531

13. Contag PR, Olomu IN, Stevenson DK, Contag CH 1998 Bioluminescent indicators in living mammals. Nat Med 4:245-247

14. Burns SM, Joh D, Francis KP, Shortliffe LD, Gruber CA, Contag PR, Contag CH 2001 Revealing the spatiotemporal patterns of bacterial infectious diseases using bioluminescent pathogens and whole body imaging. Contrib Microbiol 9:71-88

15. Arnold JW, Niesel DW, Annable CR, Hess CB, Asuncion M, Cho YJ, Peterson JW, Klimpel GR 1993 Tumor necrosis factor-alpha mediates the early pathology in Salmonella infection of the gastrointestinal tract. Microb Pathog 14:217-227

16. Sanderson KE, Stocker BAD. 1987 Salmonella typhimurium strains used in genetic analysis. In: Neidhardt FC, Ingraham JL, Low KB, Magasanik B, Schaechter M, Umbarger E (eds) Escherichia coli and Salmonella typhimurium. Cellular and Molecular Biology. American Society of Microbiology, Washington DC, pp 1220-1224

17. Hoiseth SK, Stocker BA 1981 Aromatic-dependent Salmonella typhimurium are non-virulent and effective as live vaccines. Nature 291:238-239

18. Jones BD, Falkow S 1994 Identification and characterization of a Salmonella typhimurium oxygen-regulated gene required for bacterial internalization. Infect Immun 62:3745-3752

19. Finlay BB, Falkow S 1989 Salmonella as an intracellular parasite. Mol Microbio 3:1833-1841

20. Winson MK, Swift S, Hill PJ, Sims CM, Griesmayr G, Bycroft BW, Williams P, Stewart GS 1998 Engineering the luxCDABE genes from Photorhabdus luminescens to provide a bioluminescent reporter for constitutive and promoter probe plasmids and mini-Tn5 constructs. FEMS Microbiol Lett 163:193-202
21. Winson MK, Swift S, Fish L, Throup JP, Jorgensen F, Chhabra SR, Bycroft BW, Williams P, Stewart GS 1998 Construction and analysis of luxCDABE-based plasmid sensors for investigating $\mathrm{N}$-acyl homoserine lactone-mediated quorum sensing. FEMS Microbiol Lett 163:185-192

22. Engebrecht J, Silverman M 1984 Identification of genes and gene products necessary for bacterial bioluminescence. Proc Natl Acad Sci USA 81:4154-4158

23. Burns SM, Hull SI 1998 Comparison of loss of serum resistance by defined lipopolysaccharide mutants and an acapsular mutant of uropathogenic Escherichia coli O75:K5. Infect Immun 66:4244-4253

24. Fahlen TF, Wilson RL, Boddicker JD, Jones BD 2001 Hha is a negative modulator of transcription of hilA, the Salmonella enterica serovar Typhimurium invasion gene transcriptional activator. J Bacteriol 183:6620-6629

25. Lee CA, Falkow S 1990 The ability of Salmonella to enter mammalian cells is affected by bacterial growth state. Proc Natl Acad Sci USA 87:4304-4308

26. Acred P, Hennessey TD, MacArthur-Clark JA, Merrikin DJ, Ryan DM, Smulders HC, Troke PF, Wilson RG, Straughan DW 1994 Guidelines for the welfare of animals in rodent protection tests. A report from the Rodent Protection Test Working Party. Lab Anim 28:13-18

27. Wilson BC, Jeeves WP, Lowe DM 1985 In vivo and post mortem measurements of the attenuation spectra of light in mammalian tissues. Photochem Photobiol 42:153162

28. Tromberg BJ, Shah N, Lanning R, Cerussi A, Espinoza J, Pham T, Svaasand L, Butler $\mathrm{J} 2000$ Non-invasive in vivo characterization of breast tumors using photon migration spectroscopy. Neoplasia 2:26-40

29. Jobsis FF 1977 Noninvasive, infrared monitoring of cerebral and myocardial oxygen sufficiency and circulatory parameters. Science 198:1264-1267

30. Rice BW, Cable MD, Nelson MB 2001 In vivo imaging of light-emitting probes J Biomed Opt 6:432-440

31. Edinger M, Cao YA, Hornig YS, Jenkins DE, Verneris MR, Bachmann MH, Negrin RS, Contag CH 2002 Advancing animal models of neoplasia through in vivo bioluminescence imaging. Eur J Cancer 38:2128-2136

32. Garland CD, Lee A, Dickson MR 1982 Segmented filamentous bacteria in the rodent small intestine: Their colonization of growing animals and possible role in host resistance to Salmonella. Microb Ecol 8:181-190

33. Jones BD, Ghori N, Falkow S 1994 Salmonella typhimurium initiates murine infection by penetrating and destroying the specialized epithelial $\mathrm{M}$ cells of the Peyer's patches. J Exp Med 180:15-23

34. Hill HR 1985 Host defenses in the neonate: prospects for enhancement. Semin Perinatol 9:2-11

35. Kuo S, El Guindy A, Panwala CM, Hagan PM, Camerini V 2001 Differential appearance of $\mathrm{T}$ cell subsets in the large and small intestine of neonatal mice. Pediatr Res 49:543-551

36. Berg RD 1996 The indigenous gastrointestinal microflora. Trends Microbiol 4:430 435

37. Stappenbeck TS, Hooper LV, Gordon JI 2002 Developmental regulation of intestinal angiogenesis by indigenous microbes via Paneth cells. Proc Natl Acad Sci USA 99:15451-15455

38. Hooper LV, Wong MH, Thelin A, Hansson L, Falk PG, Gordon JI 2001 Molecular analysis of commensal host-microbial relationships in the intestine. Science 291:881884

39. Hooper LV, Gordon JI 2001 Commensal host-bacterial relationships in the gut Science 292:1115-1118

40. Cummins AG, Steele TW, LaBrooy JT, Shearman DJ 1988 Maturation of the rat small intestine at weaning: changes in epithelial cell kinetics, bacterial flora, and mucosal immune activity. Gut 29:1672-1679

41. Crabbe PA, Nash DR, Bazin H, Eyssen H, Heremans JF 1970 Immunohistochemical observations on lymphoid tissues from conventional and germ-free mice. Lab Inves 22:448-457 